\title{
CONSIDERAÇÕES SOBRE O ENSINO JURÍDICO: ENTRE O DISCURSO E A TRADIÇÃO
}

\section{CONSIDERATIONS ABOUT LEGAL EDUCATION: BETWEEN THEORY AND TRADITION}

\author{
Marcel Britto ${ }^{1}$ \\ Renan Fernandes Duarte ${ }^{2}$
}

\begin{abstract}
RESUMO
O ensino de Direito veio como decorrência do desenvolvimento e independência do Brasil. Objetivava-se a formação de bacharéis, sem qualquer elemento didático efetivo, priorizando fornecer quadros para a burocracia estatal, política, administrativa e jurídica que crescia. Um modelo de ensino calcado no conteúdo formal e reprodução das normas, prosperou em todos os cursos, sedimentando práticas despreocupadas com a dimensão crítica do Direito ou mesmo os aspectos de construção de um conhecimento autêntico. Contemporaneamente, as normativas sobre os cursos jurídicos introduziram um novo paradigma, que, tão discrepante das raízes profundas, mantém-se apenas no plano do discurso.
\end{abstract}

Palavras-chave: Ensino jurídico; Direito; História; Competências.

\begin{abstract}
The teaching of law came as a result of the development and independence of Brazil. It aimed to train bachelors without any effective didactic element, providing tools for the state political, administrative and legal bureaucracy. A teaching model underpinned in the formal content and in playback of standards, prospered in all courses, solidifying reckless practices with the critical dimension of law or even with aspects of building a genuine knowledge. Contemporaneously, the regulations on legal courses introduced a new paradigm that, as discrepant deep roots, it remains only in the speech plan.
\end{abstract}

Keywords: Legal education; Law; History; Competence.

\footnotetext{
${ }^{1}$ Mestre e professor na Universidade Estadual Paulista "Júlio de Mesquita Filho" - Campus de Jaboticabal. São Paulo (Brasil). E-mail: marcelbritto@hotmail.com.

${ }^{2}$ Mestrando pela Universidade Estadual Paulista "Júlio de Mesquita Filho" - Campus de Franca. São Paulo (Brasil). E-mail: renan.f.duarte@ hotmail.com
} 


\section{INTRODUÇÃO}

Iniciando pela análise das normas disciplinadoras do Ensino de Direito, especialmente a Lei de Diretrizes e a Resolução CNE/CES n. 9 9/2004, constituintes da Política Educacional, a análise segue pelas noções de habilidades e competências, sendo que, habilidades são entendidas como um conhecimento elementar que mobilizado para um saber/fazer, quando em resposta às variadas questões postas, caracteriza a competência.

A Política Educacional, primeiro com a alteração da ênfase de um ensino centrado em currículo mínimo, priorizando um ensino crítico reflexivo em detrimento de modelo conteúdista, bem como pelo estabelecimento do perfil do egresso, introduzindo as noções habilidades e competências, alterou substancialmente o ensino com vistas a uma formação mais consentânea com a realidade do mundo contemporâneo. O estudo é dedicado a verificação dos principais aspectos determinados pela Política Educacional para os cursos de graduação em Direito e em que medida tais determinações discrepam da tendência histórica e inclusive da motivação de criação dos referidos cursos.

$\mathrm{O}$ atendimento destes aspectos da Política Educacional no ensino de Direito não tem sido pleno e tal fato se deve a diversos fatores que incluem a peculiariedade decorrente do histórico dos cursos jurídicos, passam pela questão da formação dos professores de Direito, permeiam as questões de autonomia e gestão das Instituições de Ensino Superior e desaguam em uma obliteração dos desideratos e prescrições legais.

Portanto, a mudança substancial promovida pela Política Educacional na formação dos bacharéis em Direito, sobretudo a partir da introdução das noções de habilidade e competências como aspecto da formação, rompe com a contextualização sócio histórica dos cursos.

Sem uma longa e minudente digressão histórica sobre o Direito e o Ensino de Direito no Brasil, posto que emprestaria extensão desnecessária para o âmbito do presente artigo, é imperioso traçar algumas considerações de ordem histórica e política, especialmente para o fim de que se possa compreender o fenômeno do ensino jurídico em seu contexto.

O fato de que o ensino de Direito foi e é determinado por circunstâncias que extrapolam - em muito - a intencionalidade ou as orientações de princípios excelsos de Justiça 
pode ser corroborado pelo escorço histórico - nele destacando-se desde a fase do Brasil Colônia, a chegada da família real, a independência, a república, as várias fases políticas do Estado brasileiro até os dias atuais.

Tal constatação importa para a pesquisa, pois remete a abordagem teórico metodológica de caráter crítico e dialético, com forte influxo do pensamento marxista, ao menos como ferramenta explicativa desta dimensão mais abrangente do ensino. Pela análise de aspectos pertencentes à educação em si, de onde exsurgem as diversas teorias acerca das habilidades e competências, chega-se a um panorama da mudança estrutural promovida pelas normas quanto ao ensino de Direito.

Enfim, do somatório desta análise de dúplice enfoque, se traça - como resultado de estudo - quais as implicações determinantes e decorrentes para o ensino de Direito da noção de competência.

O objetivo geral de analisar e verificar como discrepa a tradição histórica do ensino jurídico e a concepção contemporânea, preconizada pela Política Educacional será atingido por um escorço histórico resumido dos cursos de direito e pela descrição das normativas vigentes, especialmente e a Resolução CNE/CES n. ${ }^{\circ}$ 9/2004 que introduz e exige o desenvolvimento das competências como cerne no ensino de Direito.

Decorrentes desse objetivo geral emergiram, como objetivos específicos, mas orientadores da execução do presente estudo, a necessidade de conhecer a concepção de competência adotada pela Política Educacional e que, por isso, há de ser inseria nos projetos pedagógicos de todos os cursos, sendo desenvolvida pelas IES, através das estratégias de ensino propostas para essa finalidade.

Ademais, como objetivo secundário, se caracterizará o perfil do egresso - como resultado último do processo de ensino-aprendizagem, tanto de outrora, quanto de agora, para que, a partir das semelhanças e dessemelhanças no modelo de profissional, se possa concluir em que medida a norma e sua mudança de paradigma podem determinar, efetivamente, a ruptura com as práticas arraigadas de forma secular.

Quanto aos procedimentos metodológicos, para atingir os objetivos traçados realizou-se revisão bibliográfica, tanto das normas constituintes da Política Educacional para o ensino de Direito, incorporando o estudo de obras acerca das categoriais centrais de análise 
das teorias da educação e da Política Educacional, bem como de obras que fornecessem o panorama histórico de criação e desenvolvimento dos cursos jurídicos no Brasil.

Outrossim, foi coletado material versando sobre o ensino de Direito e sobre as noções de habilidades e competências. Na consecução dos objetivos, especialmente para fornecer o contraste entre o preconizado e o real, foi feita a análise dos ditames da Resolução CNE/CES N ${ }^{\circ}$ 9, de 29 de setembro de 2004, que institui as Diretrizes Curriculares Nacionais do Curso de Graduação em Direito em comparação com a prática sedimentada ao logo de quase duzentos anos de ensino jurídico no país.

Sem um aprofundamento sobre a realidade de cada curso em específico, a proposta é um comparativo teórico, ou seja, uma abordagem qualitativa sobre as normativas e a ruptura que implementam em relação ao que historicamente se consolidou, inclusive em atenção às demandas sócio históricas e econômicas.

Portanto, a pesquisa propõe e conclui sobre a grande inovação consistente em que, por meio cogente - através do poder regulamentar e disciplinar do Estado - se altere a ênfase de todo o processo de ensino-aprendizagem, agora centrado em um novo perfil do egresso. $\mathrm{O}$ meio de obtenção deste "produto" final implica em que todas as Instituições de Ensino Superior adaptem seus próprios Projetos Político Pedagógicos dos diferentes Cursos de Direito (PPPs), através de estratégias e práticas desenvolvidas pelas Instituições, tudo orientado à implementação das noções de competências e habilidades.

\section{CONTEXTO DO ENSINO JURÍDICO NO BRASIL}

Por oportuno, conquanto o termo "direito" seja polissêmico e pródiga a discussão sobre cada um de seus conceitos, por tratar-se de discussão profícua para a Ciência do Direito (ou Direito como Ciência, como para Silva (2002)), mas por ser um suposto ao presente estudo, os conceitos de direito serão visitados de forma muito perfunctória. Pela necessidade de desambiguação: o emprego do termo Direito compreende tanto o estudo das normas jurídicas, seus fundamentos e finalidades, estruturas e dinâmica, mas sempre com caráter descritivo/explicativo; quanto o somatório das normas jurídicas (abrangendo desde a Constituição - norma de mais alta hierarquia e abrangência (MORAES) - passando por todas as espécies de Leis, atos administrativos normativos, até o plano rasteiro dos atos e contratos 
jurídicos) dispostas de modo sistemático, cujo nome pode ser também ordenamento jurídico ou Direito Positivo - de caráter prescritivo/imperativo. Já o termo direito (com $d$ minúsculo) quer significar a posse por um sujeito de algum interesse juridicamente relevante, como, por exemplo: o direito a educação. Direito também pode coincidir com os augustos mandamentos do bem viver, com a ideia de Justiça, quando então, se pode nomear Direito Natural (REALE).

O ensino jurídico deve compreender - como desde sempre deveria - o trato de todas estas múltiplas dimensões ou acepções. Um dos fins colimados com a pesquisa é a constatação de efetividade disso, ou seja, em qual medida as Instituições de Ensino Superior conseguem desempenhar as funções legalmente exigidas.

Como dito alhures, o Direito a par das conceituações mais variadas, notadamente as de caráter prescritivo, também ostenta o significado coincidente com "ciência", vale dizer, o estudo de determinado objeto. Quando assim empregado, o termo direito abandona seu viés prescritivo para adotar caráter descritivo, antes de determinar como deve ser, dedica-se a explicar e analisar as instituições jurídicas.

Entretanto, ab initio o ensino de direito sempre foi impregnado de dogmatismo, a tal ponto que, conforme VENANCIO FILHO (2004), o que contribuiu para alguma mudança nos paradigmas do Direito ao longo da História do Brasil, foi menos o conteúdo e a estrutura forma das poucas faculdades de Direito e mais o ambiente que, aglutinando vários pensadores de escol, fomentou a reflexão tão necessária à qualquer ciência.

O ensino jurídico começa em meados do século XIX, tendo como marco inicial, em 11 de agosto de 1827, a criação do Curso de Ciências Jurídicas e Sociais da Academia de São Paulo e o Curso de Ciências Jurídicas e Sociais em Olinda, mais tarde seria transferido para Recife (VERBICARO, 2007). A iniciativa de criação dos cursos jurídicos deu-se em razão da necessidade de formar quadros funcionais do Estado Imperial Independente e não às expectativas e aos anseios da sociedade brasileira. Insta salientar que, desde a sua criação, os cursos jurídicos sempre estiveram sob o controle governamental, de forma que, além de estabelecer o currículo, o Estado regulava a seleção dos professores e dos compêndios a serem utilizados no ensino jurídico. Ainda não se falava em faculdade de Direito - chamavam-se Academias de Direito, nas quais o próprio Direito era cultuado como Letras Jurídicas. (SILVA, 2008). 
Acompanham o ensino jurídico no Brasil as questões relativas à própria concepção do Direito, dentre elas, inicialmente a forte influência da Igreja ao incluir em sua grade curricular, como disciplina obrigatória o Direito Eclesiástico, além de diversos decretos promulgados para adequar os cursos jurídicos do Brasil, ao sabor das necessidades, incluindo e retirando disciplinas da grade, como exemplifica NEIVA et al (2014) tem-se a consolidação da cadeira de Direito Administrativo em 1853 e futuramente a retirada da grade da disciplina de Direito Eclesiástico.

Pela relação umbilical entre Estado e Direito, o ensino jurídico, desde sua gênese, oscilou em sua conformação tal qual seu objeto o Direito e o Estado brasileiro em constante modificação, impactando também a atuação e a importância do bacharel em Direito.

Wolkmer (1998), ao considerar sobre a formação e ideologia dos atores jurídicos no século XIX, traz essa ideia de que, no contexto de uma cultura marcada pelo individualismo político e pelo formalismo legalista, a necessidade de um agente profissional que tivesse como encargo a composição dos quadros políticos burocráticos do Império e de grande parte da República, além de que com os primeiros cursos jurídicos, tornou a figura do bacharel em Direito uma constante na vida política brasileira, não pressupunha ou continha qualquer dimensão crítica e sequer capaz de extravasar o domínio enciclopédico do conteúdo legislado. Logo, dado o papel essencial dos bacharéis em Direito para a mantença do status quo, ocorre uma atribuição de prestígio para tais profissionais. Trata-se de uma questão histórica de raízes profundas e que mantém resquícios atualmente.

A relação entre educação e estruturas econômicas, políticas e sociais é expressa por Manacorda (1996) e reflete a divisão da sociedade em classes, posto que os homens travam uma luta secular para superar a divisão entre os que falam, são cultos, possuem bens materiais e detêm o poder, e aqueles outros que apenas fazem, produzem e nada possuem. Afirma o mesmo autor que a história da pedagogia e a história dos fatos pedagógicos sempre foram a história da separação dos processos educativos segundo as classes sociais. Essa compreensão, no dizer do teórico, é adequada a qualquer época histórica, sem incorrer no equívoco do presentismo, e foi bastante adequada para se compreender a 'pedagogia' que se instaurou no Brasil, desde a era Colonial, até presentemente.

Segundo Marx (2015), é na produção social da existência humana se produzem relações determinadas, necessárias e independentes da própria vontade, relações de produção 
que correspondem a um determinado grau de desenvolvimento das forças produtivas materiais. O conjunto destas relações de produção constitui a estrutura econômica da sociedade, a base concreta sobre a qual se eleva uma superestrutura jurídica e política e à qual correspondem determinadas formas de consciência social. Enfim, o modo de produção da vida material condiciona o desenvolvimento da vida social, política e intelectual em geral.

Reportando novamente a teoria marxista, há uma infraestrutura determinante das condições formais de coexistência social, de sorte que, não há como ignorar a dialética entre as forças sociais que irremediavelmente digladiam-se sobre um mesmo substrato geográfico e sob um mesmo padrão normativo (ordem constitucional e legal, positivada pelo Estado).

Esta tensão pode eclodir em distúrbios ou, mais frequentemente, mantêm-se latente, velada e encoberta pela mansidão decorrente da prevalência dos interesses que, historicamente, criam, conduzem e alteram a estrutura social. Trata-se do fenômeno da dominação que, numa estrutura positivista e formalista só seria exercida pelo aparelho intimidador e repressor - inclusive e especialmente pela via da legislação. Sem penetrar na questão crucial da legitimação do uso da força (poder), parece-nos fora de dúvida que o Estado, nem sempre faz valer o imperativo de ordem pública expresso na lei (lato senso) o que, de per si compromete o conceito, fundamento e mesmo o seu propósito, tornando o axioma Estado Democrático de Direito, como insculpido na Carta Maior de 1988, apenas um discurso ideal e vago.

Curiosamente, os mesmos profissionais que por dever de ofício deveriam guardar os comandos das leis - inclusive e especialmente a Lei Maior, com exceções honrosas, em sua maioria sempre se perfilharam ao poder estabelecido sem questionamentos, apenas beneficiando-se do "status" e vantagens inerentes à condição. Tanto o é que o Poder Judiciário é tido como um "poder técnico", não político, com o que não se pode concordar, haja vista que as decisões impactam muito fortemente todos os aspectos da vida social.

Como apregoa Marx (2015) as relações jurídicas - assim como as formas de Estado - não podem ser compreendidas por si mesmas, nem pela dita evolução geral do espírito humano, mas, inserem-se nas condições materiais de existência, assim a anatomia da sociedade civil deve ser procurada na economia política.

Portanto, resta claro que o propósito de criação dos cursos jurídicos se deu em função da demanda efetiva por profissionais sem ênfase em preocupação propedêutica e os 
conteúdos postos flutuavam ao sabor da conveniência política, mas jamais para além da legislação - ou seja, o ensino jurídico, geneticamente, se constitui apartado de qualquer dimensão reflexiva ou crítica.

É possível verificar que a proposta subjacente aos projetos pedagógicos das Faculdades de Direito, vinculadas obrigatoriamente aos padrões ditados pelo Estado, não correspondem à realidade. Há, pois, um hiato entre o papel declarado e a função ou práticas concretas, tanto no que tange ao Estado e ao Direito, quanto ao ensino de Direito. Tem-se uma frustração - deliberada ou não - das linhas estabelecidas pela Política Pública no campo educacional, notadamente expressa quanto aos cursos jurídicos.

Desde o processo de colonização até presentemente, o território nacional conformou-se de modo a satisfazer os interesses econômicos da classe dominante. Disso decorre inclusive a própria necessidade do Estado Nacional Brasileiro (advindo com a proclamação da Independência) como sequência natural do desenvolvimento das condições econômicas. Nesta medida esvazia-se o argumento bastante facilitário de que a função do Estado repousaria na consecução dos elevados interesses sociais e nos ditames do bem comum.

Quando o Estado imprime o selo geral do reconhecimento da sociedade às novas formas de ensino, quando o Estado chancela novos padrões e/ou conceitos, tem-se clara a ideia de que isso é resultante de um processo dialético no qual se batem tendências antagônicas de perpetuidade e de superação de um modelo. Permeando a tudo, tem-se a divisão da sociedade em classes, mas também o direito de a classe possuidora explorar a não-possuidora e o domínio da primeira sobre a segunda, para tanto, aponta Engels, urdiu-se o Estado.

Entretanto, exatamente pelo caráter dialético que encerra, o Estado, na edição de suas políticas, não age desbragadamente em prol da classe espoliadora, havendo momentos em que, em certos seguimentos, é possível se vislumbrar avanços. Mas, dada a conformação estrutural da dominação, mesmo que previstos pelo Direito, muitos dispositivos não são efetivos. Então, aparentemente se tem uma situação que, efetivamente não se verifica.

Justamente para não permitir que a aparência (por suas definições formais e legais) seja tomada como essência é que se impõe o dever de investigação científica.

Para SOUZA (2008), trata-se fundamentalmente de reconhecer que a ação do sujeito cognocente não é abstrata, meramente especulativa e aleatória face um mundo arbitrário, mas sobremodo a atitude de um sujeito histórico que exerce sua atividade prática 
no trato com a natureza e com a sociedade, inserido e em relação dialética com o contexto de relações e interesses que vivencia, refugindo ao determinismo, cuida-se em reconhecer a construção durante o processo de interações dos fatores históricos e materiais, vale dizer, a busca de um fim, considerando-se as contingências do trajeto.

Enfim, os fenômenos são reveladores de uma realidade subjacente, eis a essência, aferível pelo pensamento científico e filosófico (KOSIK, 2002).

Das considerações sobreditas, temos, em resumo, a hipótese de que, em dado contexto histórico, as condições reais de poder desqualificam o discurso hegemônico formal, legalista e institucionalizado em prol dos interesses de uma categoria, de um setor ou parcela dessa população. Mor das vezes, sob o aparente império da lei (discurso estatal - sem questionarmos seu componente de legitimidade) prevalecem outros interesses (admitindo-se o interesse como a vivência pragmática de um valor), consubstanciados em práticas manifestamente contra legem (PASUKANIS).

Se isto ocorre, então as formas de intervenção do Estado ou estão caquéticas ou foram perversamente construídas para revestir de legalidade algo que efetivamente não traduz a legitimidade da primazia do bem comum. Tal constatação permitiria aduzir que efetivamente os interesses econômicos exercem o poder enquanto o Estado não cumpre suas funções, frustrando os desideratos da soberania popular.

A verificação dos mecanismos de intervenção do Estado sobre os variados aspectos da vida social permite extrair elementos conclusivos acerca de quem exerce o poder e como o faz. Enfim, a atuação do Estado reflete a medida da relação de poder, tanto pela efetividade dos comandos estatais quanto pela sua pouca aderência por parte dos destinatários das normas.

Constata-se que as normas do Estado - no que tange ao ensino de Direito - não são efetivas, tal qual sucede com vários outros regramentos cujo teor prescritivo discrepa do interesse hegemônico. Descabe, ao menos no momento de cumprimento das normas, analisar o acerto das políticas que espelham. Todavia, qualquer questionamento do e sob o prisma conceitual, não deve ter o condão de solapar a efetividade das normas. Não se está em debate a questão da validade ou vigência, mas antes, da eficácia, vale dizer, do grau de aderência das normas determinantes da Política Educacional à realidade sensível dos cursos jurídicos. 
O desenvolvimento da presente pesquisa deu-se com o necessário recorte do objeto, delimitando o estudo no campo teórico, notadamente quanto ao contraste do referencial historicamente consagrado para os cursos jurídicos e o relativamente novo modelo (veiculado pela Resolução CNE/CES n. ${ }^{\circ}$, de 29 de setembro de 2004), introdutor das noções de competência e habilidades nos cursos jurídicos.

Veja-se que dar cumprimento às determinações quanto à Política Educacional impacta, as Instituições de Ensino Superior, na gestão dos respectivos cursos, na implementação de seus projetos educacionais, pela prática de seus docentes, pela abordagem metodológica, pelos materiais e recursos, mas também e sobretudo tem implicações no perfil do egresso, eis que as diretrizes curriculares estabelecidas objetivam um profissional muito diferente do que se "consagrou" na realidade brasileira.

É muito evidente o divórcio entre: as diretrizes propostas e as práticas realizadas e realizáveis no cotidiano docente, especificamente no tocante ao ensino do Direito - cuja essência já encerra enorme contradição (entre o declarado e o efetivo).

Dois aspectos importantes exsurgem do que até aqui se expôs: primeiro: o saber, como forma de poder tem sua apropriação e reprodução vinculadas diretamente às estruturas dominantes (verbi gratia, o controle estatal, as demandas do mercado etc) e, segundo: a ruptura entre a justificativa declarada dos institutos e as funções efetivamente desempenhadas, o descompasso entre o que deveria ser e o que se afere concretamente (ilustrativamente, como a própria gestão da unidade de ensino, a formação dos docentes, suas práticas pedagógicas, materiais e métodos se distanciam de efetivar as diretrizes/políticas postas).

Deixando as questões sobre Estado e Direito como um referencial comparativo em que se nota o condicionamento histórico ditado pela materialidade, bem como as suas contradições fundamentais, importa analisar com ênfase, o ensino de Direito que, prima facie, também ostenta estas mesmas contingências.

\section{O ENSINO DE DIREITO - CONTRASTE ENTRE A PROPOSTA E A TRADIÇÃO}

Enfim, feitas as observações em escala macro, principalmente sobre a raiz material, histórica, econômica e política do ensino de Direito, a sequência deve 
necessariamente tratar dos aspectos fulcrais para a área da educação, e, dentre os variados aportes teóricos, privilegiou-se aqueles que revelam as noções de competência e habilidades por serem as ditadas pela política educacional através da edição de atos administrativos normativos.

A gestão, regulação e atuação educacional pelo Estado - que consiste na política educacional - possui vários mecanismos e alguns desses meios de intervenção estão compreendidos nas funções constitucional e legalmente atribuídas ao Ministério da Educação - MEC - que, para a educação de nível superior conta com a atuação da Secretaria de Educação Superior - SESU. Há também o Conselho Nacional de Educação - CNE, assim como a Câmara de Educação Superior - CES, dentre os principais órgãos públicos.

A exemplo do que realizou LOUZADA (2010) na abordagem do ensino de administração, aqui se analisou o ensino jurídico com a verificação do seu grau de conformidade com as diretrizes propostas pelo próprio Estado, mas pautando a análise pelo prisma histórico. Destarte, o contraste entre a tradição arraigada secularmente e a novidade relativa das normas é o que marca o ensino jurídico no Brasil, permitindo aferir pela não aderência das instituições de ensino de Direito à Política Educacional.

Para tanto, fundamentais são as noções de habilidades e competências encartadas, no que pertine ao ensino de Direito, na Resolução CNE/CES n. ${ }^{\circ}$ 9, de 29 de setembro de 2004, pela qual o Estado alterou profundissimamente o modelo de ensino destes cursos, em louvável tentativa de uma adequação do processo de ensino ao que dele justa e necessariamente se espera, um egresso com capacidade crítica reflexiva e não apenas um "vomitador de leis".

O ensino, de modo bastante sumariado, compreende, essencialmente uma situação e relação dela decorrente. A relação, como se pretendeu clarear na seção anterior do presente estudo, segue as especificidades históricas de tempo e lugar. Tanto assim o é que em duas situações aparentemente iguais, bastante parecidas como o caso de um mesmo professor, lecionando a mesma disciplina, mas em duas salas distintas, obtém como resposta resultados diferentes. Portanto, todo ensino é situacional, ocorrendo conforme os aspectos históricos, variando conforme o tempo/época.

Posto isso, natural que, na medida em que as fases históricas se sucedem, também o ensino experimenta mudanças em sua conformação. 
Contudo, uma das proposições que se pode verificar com o desenvolvimento deste estudo é a ideia de que o ensino, mormente nos cursos de Direito das Instituições de Ensino Superior segue infenso a grande parte das mudanças evolutivas.

O ensino de Direito segue com seu modelo tradicional, no qual são claramente identificáveis dois polos: o docente - como sendo aquele que sabe e que, portanto, detém autoridade (corroborando, mas agora em outra escala a célebre máxima de que saber é poder) e, de outra banda, o discente - aquele que não sabe e que, por isso mesmo não ostenta voz ativa ou participação, restando apenas submeter-se ao saber autorizado da outra parte da relação.

Muito encontradiços no meio jurídico são os manuais, funcionando como ferramentas de atuação do docente sobre e para os discentes, mediando a relação. Aqui vale invocar as considerações sobreditas na introdução, pois tão arbitrária quanto a delimitação dos “saberes" que precisam ser "transmitidos" é a decisão pelo conteúdo - sempre limitado - dos manuais.

Outro componente da relação, este com forte impacto em todo o processo, é a própria Instituição de Ensino Superior, especialmente por determinar inclusive as ações e práticas docentes, seja com normatização interna (próprias da relação empregatícia), seja com a formação da matriz curricular - não raro sem a mínima intervenção de qualquer das outras duas partes fundamentais, vale dizer, alijando alunos e professores da discussão. Disso resultam conteúdos programáticos que se afiguram como seções de aflição, em que os docentes (mesmo sofrendo) são obrigados a torturarem os alunos que não compreendem minimamente o propósito de estarem nas carteiras da faculdade.

Portanto o modo de gestão da educação - relegado aos próprios agentes Instituições de Ensino Superior - não está infenso ao controle estatal que, por meio de sua política, define as diretrizes e periodicamente cobra e avalia o seu cumprimento. Todavia, a efetividade desta vinculação é questionável e objeto de investigação, pois, como é cediço, nem todas as políticas públicas conseguem saltar do plano do discurso para a realização. A gestão, ou seja, o modo pelo qual são administradas as IES representam fator importante na determinação desta adequação, juntamente com a expressão mais direta e imediata de perfilhamento que consiste na subsunção da matriz curricular aos desideratos traçados. 
A questão da autoridade que a institucionalização do ensino estabelece quebra a relação; a detenção de autoridade (quase inconteste) do docente muitas vezes transforma o estudante em refém da personalidade de quem ensina. A seu turno, dadas as contingências econômicas, os professores se veem à mercê dos mandos e desmandos das Instituições de Ensino que, impregnadas pela lógica do capital, adotam a ótica obtusa de tratar o docente como operário. Exemplifica a assertiva retro a realidade corrente de os professores terem que cumprir horários rígidos de início e fim das aulas. Cada aula - em complementação ao dito anteriormente - traz peculiariedades.

Por óbvio, não se olvida o aspecto dialógico que toda relação encerra, mas de maneira geral, o ensino - e se aborda aqui com foco no ensino jurídico - remanesce como um sistema fechado de transmissão. Tendo o modelo tradicional de ensino a conformação que se alinhavou, ocorre o descarte da capacidade de pensar. Eis a importância das noções de habilidades e competências, pois é justamente essa condição: de reflexão, de saber aprender, de desenvolver o raciocínio lógico o que se preconiza, hodiernamente, pelas resoluções normativas da matriz curricular.

O pensamento e a capacidade de seu desenvolvimento, aprimoramento e adaptação à diferentes situações - consistente no objetivo último das normas regulamentadoras como essencial ao egresso - passa ao largo nos processos de ensino aprendizagem de base organizacional e institucional do modelo tradicional. Imaginando a situação do ensino como a relação entre a tríade: professor, escola e aluno, o sistema fechado de ênfase na transmissão descarta a capacidade de pensar, posto ser desnecessário e até mesmo "contraproducente".

Remanescem alguns estigmas no ensino de Direito, tais como a concepção errônea de que o conhecimento está pronto e acabado e a admissão única e exclusiva da certeza, com sua premiação em contraste com a punição da dúvida e a execração do erro (tão necessário no processo de conhecimento).

Ademais, no campo do Direito, o exercício do raciocínio sobre os temas e as situações se opõe fortemente ao sentimento arraigado de uma "sacralização" do Direito. Destarte, só restaria mesmo o sistema de reprodução do conhecimento. Ineludivelmente o professor reproduz o sistema em que se formou. As normas gerais estabelecidas pelo Estado e que integram sua política para a educação muitas vezes passa ao largo da realidade praticada. 
Tem-se, pois, um óbice ao desenvolvimento e aprimoramento do trabalho docente e franca frustração da política educacional determinada pela via da gestão da entidade de ensino.

Some-se a isto o fato de que o mundo imprime ritmo cada dia mais acelerado, seria como um grupo caminhando pretender alcançar uma locomotiva. A História da humanidade é a história das transformações (a própria linha da História traz como marcos os eventos que tiveram a propriedade de alterar muito o modus vivendi). É cediço que mudanças sempre existiram, mas a modernidade trouxe não apenas uma velocidade vertiginosa e difícil de acompanhar, mas também muito maior grau de incertezas. A instabilidade, a incerteza, sempre houve, mas se podia contar com um mínimo de segurança, um referencial pretensamente mais sólido. Também nos dizeres de Marx, celebrizado por Marshall Berman (1986), tudo o que é sólido e estável se volatiliza (tudo o que é sólido desmancha no ar).

Confirmam estas considerações a mera constatação de como eram e como são os transportes. A comunicação instantânea e global, a informática e todos os avanços tecnológicos impactaram a vida - tanto pessoal como profissional, imprimindo velocidade, transitoriedade.

Entretanto, nota-se um descompasso, o ensino de Direito não acompanhou a marcha imposta pelos avanços técnicos e tecnológicos, conservando-se por várias razões nos moldes traçados em seus primórdios.

A notícia demorava a chegar. A diferença no tempo de acontecimento do evento até seu conhecimento por terceiros era absurda se comparada com a instantaneidade da informação contemporânea (verbi gratia: uma ordenação real emanada da metrópole portuguesa tardava, pelo menos três meses para cruzar o atlântico e espraiar-se pelas terras virginais da colônia brasileira). Ainda hoje há resquícios de dispositivos legais que contemplam - sem qualquer utilidade e por isso carentes de propósito - esse aspecto de delay, como é o caso do previsto em uma norma fundamental não só para a aplicação do Direito como para sua compreensão, a Lei de Introdução às Normas do Direito Brasileiro - em seu $\S 1^{\circ}$ do art. $1^{\circ}$. Indicativo do apego do Direito ao velho.

A pós-modernidade caracterizada pela velocidade das mudanças e pela maior e crescente imprevisibilidade faz com que novos problemas e questões surjam instantaneamente. Como as soluções e respostas não estão prontas, tem-se a inadequação do 
modelo de ensino calcado na reprodução. Com efeito, o ensino tradicional não consegue atender o que se espera.

Consoante a moderna noção de educação, educar pode definir-se simplória, mas acertadamente como: preparar para o imprevisto. O panorama revela um quadro de grande velocidade dos eventos, grande quantidade tanto de eventos quanto de informações e uma disponibilidade bastante variada. Tais fatores, por si só levam à alteração da concepção e visão que se tinha do professor de Direito - outrora única fonte do conhecimento - hoje não precisa saber o conteúdo da legislação e jurisprudência para, na forma de vasos comunicantes, despejar para os alunos - mas, antes, construir conjuntamente com os estudantes meios de desenvolvimento do pensamento que plástica e rapidamente possa além de coletar as informações necessárias, aplica-las com correção a e propriedade às situações propostas.

Impossível competir com os meios tecnológicos (eletrônicos) de armazenamento de informação. Facilmente se obtém acesso a todo o repertório legislativo e jurisprudencial quando, como e de onde se quiser. É preciso saber buscar a informação; desenvolver mecanismo seletivo de busca quanto às informações requeridas e, sobretudo, ser crítico. A criticidade aqui se emprega no sentido técnico, ou seja, implica raciocínio: exercício intelectual sobre determinado objeto, aplicando procedimentos criteriosos.

Eis os motivos pelos quais a sistemática anterior de ensino - calcada na reprodução - não se coaduna com a realidade. A transmissão acrítica de conteúdos (conquanto extensos) dispensa o que hoje é mais valorizado, o uso do raciocínio.

A crítica - como momento de reflexão sobre a realidade - é essencial. A educação, a didática, o ensino não podem ficar desgarrados da vida, da concretude material. A sala de aula não pode ser tida como um mundo à parte, especial, até porque a existência do ensino se justifica para preparar para o mundo especial, mas não exclusivamente, profissional.

Sem as características de plasticidade, adaptabilidade e criticidade o conhecimento é estéril no cotidiano. O novo foco para o ensino de Direito deve ser dado (como determinado pelo próprio Estado - via de sua Política Educacional) com necessária associação a um conhecimento em construção. A Lei de Diretrizes e Bases - Lei n 9.394/1996, ao preconizar pelas diretrizes curriculares em substituição ao currículo mínimo e ao definir o perfil do egresso fez clara opção para um novo ensino em substituição ao antigo, centrado em conteúdos, ou nos dizeres de Paulo Freire: ensino "bancário". Diante do desaparecimento das 
certezas, necessário se faz trocar a transmissão pela construção do conhecimento, cuida-se do ensino problematizador.

A Resolução CNE/CES n. ${ }^{\circ}$ 9, de 29 de setembro de 2004, ao introduzir a noção de habilidades e competências estabeleceu o perfil do graduando a que se chega apenas com a construção criativa do saber, através da transmissão crítica. Por isso mesmo, o erro não pode ser abominado. É pelo erro que se chega à ideia correta - trata-se do valor pedagógico do erro. Não é mais o tempo em que duvidar representava perda de autoridade ou indicava pouco saber. Eis as linhas mestras da Política Educacional para os cursos de Direito.

O mundo da pesquisa e da ciência é ambiente de convivência necessária com a dúvida. Conferir importância ao erro e ainda mais à dúvida é o que permite à ciência uma conexão com o mundo real. Ocorre que, no ensino jurídico os docentes são considerados apenas pela sua titulação o que não conduz a ostentar uma boa formação pedagógica. Muitas vezes os títulos não garantem a junção do conhecimento teórico e a capacidade de ensinar.

Ao passo em que cada indivíduo é o resultante das histórias e vivências de sua formação, isso induz à reprodução dos modelos experimentados. Mal comparando a situação é análoga a de alguém que está sedado, acomodado. A mudança desacomoda, incomoda, por isso mesmo provoca uma reação natural à insegurança.

Raros são os que desejam enxergar a insegurança. Todavia, não reconhecer o fato não o faz desaparecer. O aparato institucional, por muito tempo, contribuiu para essa obliteração, mas já não é mais assim, posto que as normas definidoras das diretrizes curriculares, atualmente, preconizam por esse novo saber. $\mathrm{O}$ novo saber demanda um novo ensino e, por conseguinte, o novo ensino clama por uma nova formação docente e novas práticas em sala de aula.

A Política Educacional do Estado revelou-se sensível à necessidade de adequação do ensino às novas conformações sociais e profissionais, exigindo que, para a caracterização do egresso, em seu perfil se incluíssem as noções de habilidade e competência.

A realidade alterou a crença geral e disseminada de que o diploma de curso superior em Direito representava uma espécie de "carta de alforria", um "passaporte para a elevação do patamar de vida”. O título de bacharel em Direito, de per si, não representa mais do que a conclusão do nível superior de ensino, pois adquiriu outro sentido político: outrora era a garantia de abastança material pela função desempenhada, mas, contemporaneamente 
ocorre acirrada concorrência que permite a diferenciação entre os egressos e assim perpetua as relações de dominação.

Neste sentido, resta evidente o divórcio entre a teoria determinada pelas normas e a prática que se estende desde o Império. As ações, práticas, estratégias e gestões das Instituições de Ensino Superior não se perfilham ao que deveria ser, sequer do ponto de vista de adequação formal aos desideratos.

Com o impulso dado por incentivos governamentais, especialmente financiamentos estudantis dentre outros programas, é fato o aumento da demanda pelos cursos de Direito, acrescendo fator novo na maneira pela qual as Instituições de Ensino Superior gerem sua estrutura e serviços - inclusive e especialmente com vistas aos resultados (econômicos e de desempenho).

Diante desse panorama, emerge uma questão que norteia a pesquisa: até que ponto o ensino de Direito está conforme as determinações emanadas da Política Educacional!? Como e em que grau as Faculdades de Direito, através de seus Projetos Político Pedagógicos, estratégias, materiais, métodos e corpo docente e discente faz valer as disposições legais sobre o perfil do egresso na inclusão e desenvolvimento de habilidades e competências?

Com a reunião de elementos bibliográficos, desde o surgimento até a mudança de paradigma proposta pelas normas, é clara a inadequação entre o discurso e a prática.

\section{CONCLUSÕES}

Pela análise histórica do papel desempenhado pelos bacharéis em Direito, desde a fundação dos primeiros cursos jurídicos no Brasil, em 11 de agosto de 1827, com a criação dos Cursos de São Paulo e Olinda, percebe-se o claro interesse em formar quadros para a burocracia do Estado que se formava e afirmava como nação independente.

Não por acaso, a ideia era criar a própria matriz de formação daqueles que seriam ocupantes de prestígio das funções não apenas jurídicas, mas legislativas e governamentais do Brasil. 
Todavia, a preocupação com o profissional não perpassava nos campos propedêuticos ou didáticos, vez que, historicamente se privilegiou como docentes "profissionais de Direito que ensinam" e não "profissionais do ensino que lecionam Direito"!

Essa tradição - cristalizada por quase duzentos anos segue inabalável e quase inalterada, mesmo apesar da edição de novas normas disciplinadoras do ensino jurídico, como a Lei de Diretrizes e Bases da Educação e especialmente a Resolução CNE/CES n. . 9/2004.

Por meio desta última norma, resta assente a ênfase nas competências e habilidades que devem pautar todo o processo de ensino e aprendizagem. Não são poucas as implicações decorrentes, desde uma mudança de paradigma teórico - substituindo o ensino calcado na hierarquia de cátedra, no modelo "bancário" ou conteudista para uma formação dinâmica que explore as potencialidades dos alunos com vistas à sua adaptação dinâmica e constante.

Enfim, há que se preconizar um ensino que permita o aprender constante em substituição ao modelo monolítico e ultrapassado que servia como limitante inclusive de teorias críticas sobre o Direito e sua prática.

A despeito do caráter cogente das novas normas disciplinadoras do currículo mínimo para os cursos jurídicos, encerrando uma contradição muito encontrável em todo o universo normativo, verifica-se a ineficácia das prescrições. De modo coloquial, é possível concluir que, se algo foi urdido para não funcionar e não funciona, logo esse algo funciona.

Vale dizer que, o hiato entre discurso e prática é revelador da intencionalidade subjacente, qual seja a mantença da situação defasada e superada do ensino jurídico.

Negando-se efetividade às normativas, não se está apenas descumprindo a legalidade e tornando inadequados os currículos, mas antes, se compromete a formação dos bacharéis que, herdam de um passado rançoso o triste objetivo de manterem o status quo mesmo que a custo do justo. Assim, preconiza-se o direito positivo em detrimento do ideal de bem comum e interesse social. No lugar de um ensino dinâmico voltado para além das demandas do mercado de trabalho, tem-se a reprodução de profissionais que aplicam o direito de forma acrítica e mecânica. 


\section{REFERÊNCIAS}

ADORNO, Sérgio. Os aprendizes do poder - o bacharelismo liberal na política brasileira. Rio de Janeiro: Paz e Terra, 1988.

BERMAN, Marshall. Tudo o que é sólido desmancha no ar - a aventura da posmodernidade. São Paulo: Companhia das Letras, 1986.

BOBBIO, Norberto. Teoria do ordenamento jurídico. 10. ed. Brasília: Editora UNB, 1999.

BOURDIEU, Pierre. Os três estados do Capital Cultural. IN: NOGEUIRA, M. A.; CATANI, A. Escritos sobre a Educação. Petrópolis: Vozes, 1998.

BRASIL. Lei nº 9.394, de 20 de dezembro de 1996. Lei de Diretrizes e Bases da Educação Nacional Disponível em < www.inep.gov.br >. Acesso em 12 fev.2016.

BRASIL. Decreto-Lei no 4.657, de 4 de setembro de 1942. Lei de Introdução às normas do Direito Brasileiro. Disponível em <http://www.planalto.gov.br/ccivil_03/decreto-lei/Del4657compilado.htm>. Acessado em 20 jan. 2016

BRAVERMAN, Harry. Trabalho e capital monopolista - a degradação do trabalho no século XX. 3. ed. Rio de Janeiro: Zahar Editores, 1981.

CONSELHO NACIONAL DE EDUCAÇÃO - CNE. Resolução N. ${ }^{\circ 9}$, de 29 de setembro de 2004. Disponível em < www.inep.gov.br >. Acesso em 02.fev.2016.

CRETELla JÚNIOR, José. Curso de filosofia do direito. 8. ed. São Paulo: Forense, 2002.

ENGELS, Friedrich. A origem da família, da propriedade privada e do Estado.15. ed. Rio de Janeiro: Bertrand Brasil, 2000.

FAORO, Raymundo. Os donos do poder: formação do patronato político brasileiro.10. ed. São Paulo: Globo: Publifolha, 2000. v. I e II.

HESPANHA, Antonio M. A história do direito na história social. Lisboa: Livros Horizonte, 1977.

KOSIK, Karel. Dialética do concreto. Rio de Janeiro: Paz e Terra, 2002. 
LE BOTERF, G. Desenvolvendo a competência dos Profissionais. Porto Alegre, Artmed, 2003.

LOUZADA, Roberto. A noção de competência e o ensino de Administração: um estudo multicascos. Tese de Doutorado defendida junto ao Programa de Pós-Graduação da FCLAR - UNESP - campus de Araraquara, 2010.

MANACORDA, Mário Alighiero. História da Educação: da Antiguidade aos nossos dias. (Trad.) Gaetano Lo Monaco. São Paulo: Cortez, 1996.

MARX, Karl. Contribuição à crítica da economia política. São Paulo: Folha de São Paulo, 2015.

MACEDO, Lino de. Situação-problema: forma e recurso de avaliação, desenvolvimento de competências e aprendizagem escolar. IN: As Competências para ensinar no Século XXI. Porto Alegre: Artmed, 2002.

MORAES, Alexandre de. Constituição do Brasil interpretada e legislação constitucional. 4. ed. São Paulo: Atlas, 2004.

MOREIRA, Vital. A ordem jurídica do capitalismo. 4. ed. Lisboa: Editorial Caminho, 1987.

NEIVA, Delander da Silva; et al. A influência do contexto histórico do ensino jurídico brasileiro na formação de profissionais acríticos e o papel do educador. Faculdade Athenas, 2014. Disponível em

<http://www.atenas.edu.br/Faculdade/arquivos/NucleoIniciacaoCiencia/REVISTAJURI2013 13\%20A\%20INFLU\%C3\%8ANCIA\%20DO\%20CONTEXTO\%20HIST\%C3\%93RICO\%20 DO\%20ENSINO\%20JUR\%C3\%8DDICO\%20BRASILEIRO\%20NA\%20FORMA\%C3\%87 \%C3\%830\%20DE\%20PROFISSIONAIS\%20ACR\%C3\%8DTICOS\%20E\%200\%20PAPE L\%20DO\%20EDUCADOR.PDF> Acesso em: 17 jan. 2016.

PACHUKANIS, Evgeny Bronislavovitch. A teoria geral do direito e o marxismo. Coimbra: Centelha, 1977.

PERRENOUD, P. Construir as Competências desde a Escola. Porto Alegre: Artmed, 1999. SILVA, Elza Maria Tavares. Ensino de Direito no Brasil: perspectivas históricas gerais. Universidade de Mogi das Cruzes (UMC), 2008. Disponível em <http://www.scielo.br/pdf/pee/v4n1/v4n1a08)>. Acesso em 20 jan. 2016 
SILVA, De Plácido e. Vocabulário jurídico. 20. ed. Rio de Janeiro: Editora Forense, 2002.

SOUZA, José Gilberto de. Questão de método: uma análise sobre o padrão de homogeneização do território rural paulista. Jaboticabal, São Paulo FCAVJ/UNESP, 2008. (Tese de Livre Docência)

TANGUY, L. (org.). Saberes e competências: o uso de tais noções na escola e na empresa. Campinas, Papirus, 1997.

VERBICARO, Loiane Prado. Ensino jurídico brasileiro e o direito crítico e reflexivo. Jus Navigandi, Teresina, ano 12, n. 1501, 11 ago. 2007. Disponível em: <http://jus.com.br/revista/texto/10281>. Acesso em: 17 jan. 2016.

VENANCIO FILHO, Alberto. Das arcadas ao bacharelismo: 150 anos de ensino jurídico no Brasil. 2. ed. São Paulo: Perspectiva, 2004.

WOLKMER, Antonio Carlos. História do Direito no Brasil. Rio de Janeiro: Forense, 1998. WOLKMER, Antonio Carlos. Instituições e pluralismo na formação do direito brasileiro. IN.Teoria do direito e do Estado. Porto Alegre: Fabris, 2006. 